\title{
The Role of Royalties in Resource Extraction Contracts
}

$\begin{array}{ccc}\text { Robert } & \text { Bryce } & \text { Denis } \\ \text { Conrad } & \text { Hool } & \text { Nekipelov } \\ \text { Duke } & \begin{array}{c}\text { Singapore } \\ \text { University } \\ \text { Unagement } \\ \text { University }\end{array} & \begin{array}{c}\text { University of } \\ \text { Virginia }\end{array}\end{array}$

September 30, 2015

ERID Working Paper Number 195

This paper can be downloaded without charge from the Social Science Research Network Electronic Paper Collection:

http://ssrn.com/abstract=2668253

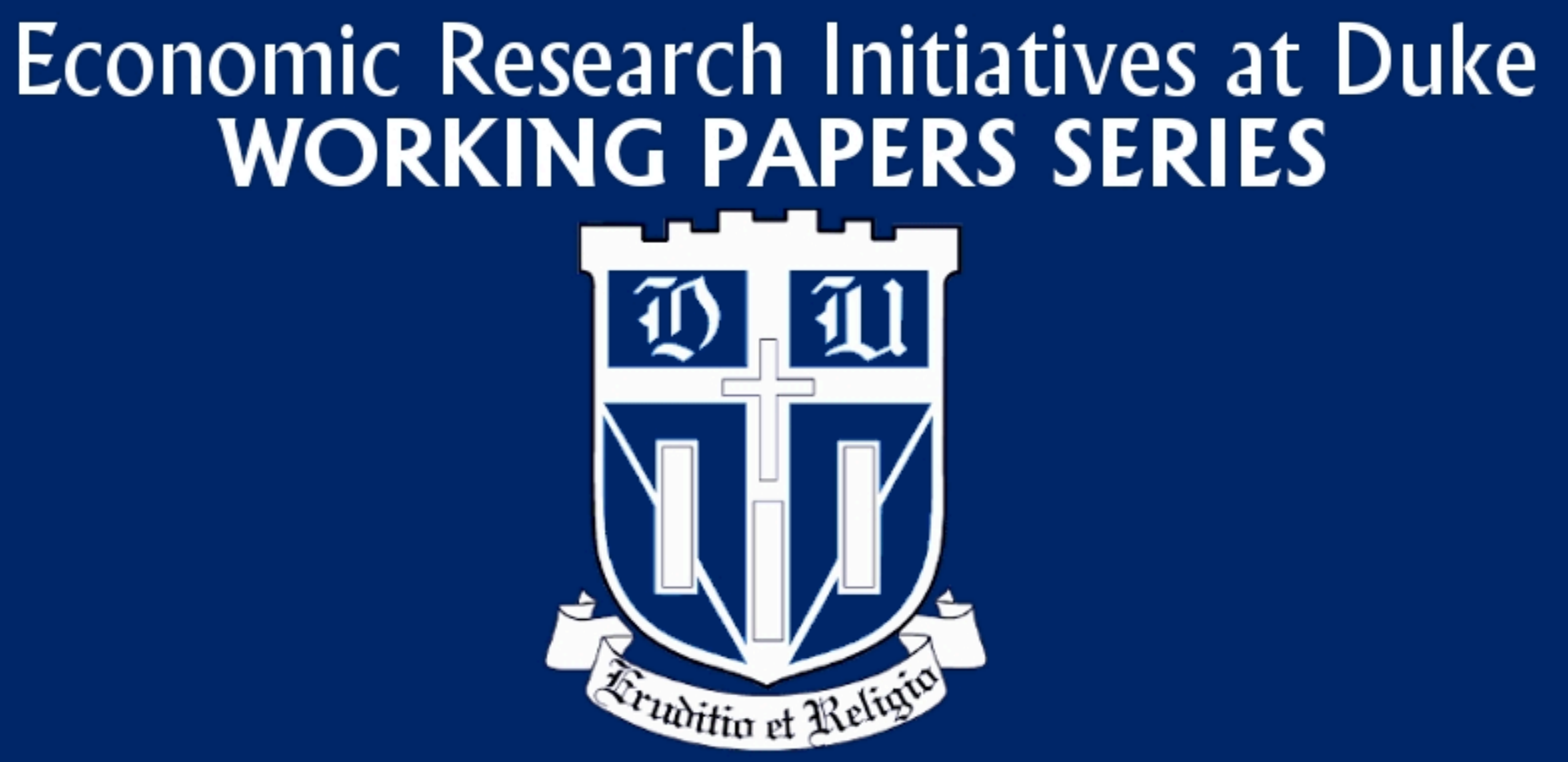




\title{
The Role of Royalties in Resource Extraction Contracts
}

\author{
Robert F. Conrad ${ }^{a}$, Bryce Hool ${ }^{b}$ and Denis Nekipelov ${ }^{c}$ \\ ${ }^{a}$ Corresponding author, Associate Professor of Public Policy Studies and Economics, \\ Duke University; ${ }^{b}$ Professor of Economics, Singapore Management University; \\ ${ }^{c}$ Associate Professor of Economics and Computer Science, University of Virginia
}

This Version: September 2015

\begin{abstract}
The manner in which governments charge mineral resource producers has been the subject of considerable debate. In particular, there is a continuing debate about whether royalties should be reduced or eliminated, the preferred alternative then being some variant of an income-based charge such as a resource rent tax, a policy adopted in Norway, the United Kingdom and Australia. The argument for avoiding royalties is based on analyses demonstrating that royalties and other quantity-based charges distort production decisions and lead to outcomes such as high-grading and premature mine closure. We argue that it is inappropriate to infer that royalties are inefficient from the perspective of the resource owner (typically a government on behalf of society). Rather, the royalty serves a key pricing purpose and should be interpreted as the capital loss on the resource owner's balance sheet from extracting marginal reserves. We demonstrate this result under various conditions of uncertainty and informational asymmetry, using an incentive-based framework which enables us to highlight the separation of asset ownership from asset use. The principal-agent framework is consistent with the contracting problem encountered by governments who as resource owners contract with private sector firms for extraction rights.
\end{abstract}

JEL Classification: H21, H25, Q38

Keywords: Natural resource taxation; optimal mining royalty; asymmetric information 


\section{Introduction}

The theoretical and practical challenges of designing a fiscal regime for the extraction of an exhaustible mineral resource have generated a substantial economics literature and considerable debate amongst policy-makers, independent advisers, and resource producers. ${ }^{1}$ The choice of instruments and their role in a fiscal regime is influenced potentially by many considerations whose relative importance varies with the particular circumstances of the resource and the jurisdiction in which it is located. ${ }^{2} \mathrm{~A}$ common feature of the design problem, however, is the desire to achieve an acceptable return for the resource owner - most often a government on behalf of the public in an economically efficient manner. In this regard, it is frequently argued that the optimal device is a profit-sharing arrangement, and that quantitybased royalties (ad rem or ad valorem) should be avoided because they distort incentives and create inefficiencies.

It is important not to lose sight of the fact that efficiency and optimality are relative to the objective specified. In the analyses that have led to the conclusion that royalties distort incentives, the typical goal is maximization of the expected net present value (profit) obtained from extraction, generally from the perspective of a single resource producer. ${ }^{3}$ No weight is given to the impact of extraction on other measures of material concern to the owner, whether society or private individual; implicitly, at least, the opportunity cost of extraction is zero. These analyses have been mainly concerned with intertemporal extraction profiles (the timing and quantity of resource extracted) when reserve extraction is less than complete (see, for example, Conrad and Hool 1985; Otto et al. 2006) but have also addressed risk-sharing when the value of a mining tract is uncertain (Leland 1978). The introduction of a royalty alters the firm's efficiency (profit-maximizing) conditions and creates a tendency for the firm to extract the resource more rapidly and to shut down mining operations earlier, leaving otherwise valuable reserves in the ground. In this context, pure profit-sharing provides a non-distortionary means of sharing risk and preserving production efficiency.

\footnotetext{
${ }^{1}$ Recent reviews can be found in Boadway and Keen 2010; Otto et al. 2006; and Hogan and Goldsworthy 2010.

${ }^{2}$ Boadway and Keen 2010 provide a comprehensive analysis.

${ }^{3}$ A typical example is Garnaut and Clunies Ross (1983) where the objective function is simply maximization of the present value from extraction either from the perspective of the producer or without regard to ownership.
} 
These conclusions have led naturally to the advocacy of profit-sharing schemes, among which resource rent taxes in particular have enjoyed some increased popularity, and a movement away from royalties in resource contracts. Advice by major international financial institutions also has placed emphasis on "rent" charges, while accepting the need for modest royalties despite their claimed disadvantages (IMF 2012, Otto et al. 2006, and Baunsgaard 2012). In addition, as noted by the IMF (IMF 2012, Box 3), high-income countries, with the notable exception of the United States, have moved away from royalties and replaced them with income-based charges. In contrast to this trend, there are recent examples of countries (including Mongolia and Zambia) where royalty rates have been increased. ${ }^{4}$

The debate about the merits of royalties relative to profits charges is empirically important because countries vary with respect to application. The differences result in part from the economic framework used to evaluate the policies and, as we have noted, the view that royalties are economically inefficient. These differences are seen in Table 1 where relevant provisions for the issue at hand are summarized for some petroleum-producing countries. We note that all countries impose a standard profits tax which is generally applicable, perhaps at different rates, to all economic sectors. In our analysis of the roles of royalties (production-based charges) and income-based charges, we take as given the generally applicable profits tax regime. ${ }^{5}$

The contrast is most starkly illustrated by comparing the United States (federal offshore) and Canada (Alberta) with the United Kingdom, Australia and Norway. ${ }^{6}$ The United States and Canada (Alberta) employ production charges as a basis for computing the factor payment while countries in the latter group have eliminated production-based royalties and substituted

\footnotetext{
${ }^{4}$ Mongolia introduced a surtax royalty with rates that vary by mineral in 2011 (Ernst and Young 2012). In 2013 Mongolia also increased the royalty on gold (http://www.infomongolia.com/ct/ci/7348). Zambia has increased the base royalty on copper to $6 \%$ (Conrad 2014).

${ }^{5}$ We note also that contractual form does not in itself have economic relevance for the outcome. For instance, a production sharing contract in its pure form is effectively a resource rent tax (profits-based charge) with a zero interest rate applied to the cash flow and is equivalent to such a charge imposed in a more traditional lease contract. See Alexeev and Conrad (2014).

${ }^{6}$ The United Kingdom, Australia and Norway all used royalties when production was just starting, returns were high, fields were large, and costs were relatively low. They have moved to profits-based charges for only marginal fields or, perhaps, marginal production where royalties were paid for many years and now costs are high.
} 
resource rent taxes or excess profits charges literally in lieu of royalties. The Australian system is the most clearly aligned with the Garnaut Clunies Ross framework (see the Policy Transition Group (2010) study and the Report to the Treasurer (2009) on Australian tax reform) but it is clear that the United Kingdom, Indonesia and Norway have replaced royalties with a type of profits-based charge in addition to the standard profits tax. These charges are limited exclusively to natural resource production and thus are further evidence of the natural resource basis of the charge.

The United States, on the other hand, has a standard flat rate ad valorem charge which corresponds to the historical and current treatment of factor payments in private ownership economies. In particular, private owners of reserves in the United States use royalties as do oil companies who retain an interest in operations where production is contracted to others. Such royalties paid to those who retain an interest are called overriding royalties. Property rights to reserves are vested in the Canadian provisions. Alberta's royalties, which are per unit and have rates which vary with both price and quantity, are evidence of property ownership whereas the central government in Canada imposes no such charge, because the mineral rights are held by the Canadian provinces.

Other countries employ a combination of royalties and excess profits taxes (production sharing). Some countries use a sliding scale for royalties based on geological characteristics (e.g., the Netherlands, Kazakhstan, and Nigeria) while others are flat rate (e.g., Azerbaijan). China's excess profits tax is really a production-based charge and thus should technically be regarded as similar to the one employed in Alberta.

The profits-based charge might be variable, based on either rates of return (e.g., Ghana) or net present value. In addition, a carried interest such as the one used in Ghana might be a type of profits charge depending on the interest rate used to compute the carry.

Finally, the Iraqi system is based on a service contract arrangement. Under this regime, no royalty is charged because the producer is simply supplying a service and the government retains the rights to all production and sales. Thus, the efficiency issue in this case, as will be shown, is whether the government determines the extraction profile (implicitly using the shadow price to determine the extraction profile via internal prices). The contractor is then paid a service fee (like a law firm) in exchange for the services provided. Such a fee, however, has risk sharing characteristics in that the fee is based on the overall profitability of the property. 
Given the variation in practice despite the widespread condemnation of royalties, it is important to revisit the question of efficient payment schemes. The practice of applying royalties might be more in accord with efficiency than either the advice to the contrary or the theory upon which that advice is based. In particular, we will demonstrate that there is an essential role for royalties in mineral extraction contracts. This conclusion is not inconsistent with the body of analysis referred to above but follows from taking a different perspective on what is the appropriate problem to be solved, departing from the previous literature in two significant, related respects. First, we account for the fact that the opportunity cost of extracting reserves will typically not be zero even in the absence of physical exhaustion of the resource during the extraction period. Second, we view the determination of optimal mineral resource payments not as a taxation problem but as a contracting problem; specifically, a principal-agent problem where property rights are clearly defined and the objectives of the resource owner (typically the government) and the extracting firm are not generally aligned. ${ }^{7}$

We argue that there are fundamental reasons to view the determination of the optimal resource payment structure from a perspective that differs from the maximization of economic rent from extraction assuming the opportunity cost of extraction is zero. In other words, the discrediting of royalties has been based on analyses of the wrong formulation of the problem. When the government's objective is no longer congruent with the extracting firm's goal of private profit-maximization, it will in general be necessary to align the firm's incentive in order to achieve social efficiency. It should be emphasized that while we are framing this problem in terms of government as the owner of the resource (the principal), the fundamental issue is accounting properly for opportunity cost. Assuming private ownership would alter neither the nature of the argument nor its implications.

The principal-agent structure is a natural one in the present context because of the separation of ownership of reserves from the extraction decision, as well as the uncertainty, informational asymmetry, and limited observ-

\footnotetext{
${ }^{7}$ The reason that firms contract with governments for extraction rights is the simple fact that the government holds the mineral rights. Otherwise, the contracting problem would be between private agents as is the case in the United States where mineral rights can be vested in private hands. It is important to note that the use of the principal-agent framework is not necessary to demonstrate the efficiency of the royalty. We show below that the royalty is the price that would otherwise be reflected in a market for reserves or as the opportunity cost of a productive factor in the case of efficient state ownership.
} 
ability that characterize mineral exploitation and need to be considered in optimal contract design. We begin by abstracting for the most part from these important features, in order to demonstrate that the argument for using royalties does not depend on the complexities arising from uncertainty and information issues. We show that even in conditions of certainty and complete information, it will generally be optimal to have a per unit charge imposed on extraction. Further, this royalty can (and should) be interpreted as the payment for a scarce factor of production - the price of reserves that will equilibrate supply and demand for the extractable resource and maximize the surplus available to be distributed to both parties to the contract. In this regard, the mineral reserves are no different from any productive input such as labor, and a royalty as the price of reserves is no different than a wage rate as the price of labor.

We then proceed to show that the presence of uncertainty, though complicating the analysis, does not fundamentally alter the nature of the problem. The form taken by the optimal royalty in this context is a natural generalization of the royalty in the case of certainty.

\section{Context}

There are a number of potential factors underpinning the formulation of the resource owner's problem proposed here. Broadly speaking, they relate to three fundamental concepts: property rights, rent, and opportunity cost.

(i) Property rights. Governments should not be regarded - or regard themselves - simply as tax collectors in the mineral production process. As the owner, on behalf of society, of the reserves of an exhaustible natural resource, a government owns the stock of a factor of production (reserves) from which a flow (extraction) is made possible. Reserves are an asset on the resource owner's (and society's) balance sheet. When mineral assets are held by the state, the value of reserves should be reflected on the state's balance sheet just like assets used to produce other publicly-provided goods and services such as mail delivery, highway services, and even steel and electricity, depending on the degree of state participation in the economy. The fact that the mineral reserves are a gift of nature and were thus free to the government does not alter this; nor does the fact that the mineral extracting firm may have acquired the rights, for some period, to extract the resource. Title to the stock of reserves is not transferred to the extracting firm when the reserves 
are held by the state. ${ }^{8}$ The government owns the initial stock of reserves and it owns the remaining stock - plus any residual value of the land or sea - after the lease expires. It is the quantity of the reserves being extracted that is being sold from the resource owner's inventory, as well as the lease rights to use the property (surface rights and other real property) for a specified time period. ${ }^{9}$

The fact that extraction rights may be granted for a long period, and potentially be renewable, does not vitiate this point. If indeed this did amount to a de facto transfer of property rights, the firm should then internalize the shadow price of the reserves. ${ }^{10}$ If there were an actual transfer of property rights, as permitted with private property in the United States, then the extracting firm would be able to dispose of the property and recover the value of its surface or subsurface rights after the closure of the mine. In this case, the opportunity cost would be fully taken into account as if a royalty had been imposed.

(ii) Rent. Consequently, except in instances where private property rights include mineral rights, it is the government that has claim to the resource rent, defined here as the return to the scarce productive factor. The resource rent will be capitalized into the price of the asset (the reserves and the land or sea that contains the reserves) and be reflected as an asset value on the government's balance sheet. The value of the combined asset base will be the maximum value of its use, which may or may not involve extracting reserves in the present or at any time in the future. ${ }^{11}$

(iii) Opportunity cost. Society's opportunity cost of using the resource

\footnotetext{
${ }^{8}$ In the United States, private property rights include the reserves. Consequently, any person holding land may transfer all of the land rights, including the reserves, and maintain no economic interest in the property. Alternatively, it is possible for owners to unbundle the property rights by selling surface (and related) rights, while retaining the mineral rights.

${ }^{9}$ The use value of the entire deposit will generally not be zero for the investor. The use value, on a flow basis, includes extraction, pressure (in oil deposits), and the physical structure of the deposit.

${ }^{10}$ If the resource producer internalizes the opportunity cost of reserves, then a royalty charged by the resource owner can still be efficient. The royalty can then be perceived as a transfer with no efficiency effects. For instance, a royalty that rises at the rate of interest in the original Hotelling model would equate to such a transfer (see Hotelling 1931).

${ }^{11}$ The maximum present value of the property might be achieved by some means other than extraction. For instance, the present value of an oil tract might be $\$ 10$ billion dollars but the value of the tract for real estate development might be $\$ 15$ billion if the tract is located in central Paris or midtown Manhattan.
} 
(having reserves extracted by a particular firm at a particular time in a specified amount) might be determined by any of the following alternatives: (i) keeping the reserves in the ground; (ii) using the surface rights for some other activity such as farming, housing, fishing, or other recreational or productive pursuits; (iii) selling the reserves for the market price (lump sum) and not retaining any economic interest in the residual value of the property ${ }^{12}$; (iv) leasing the reserves to a different firm; or (v) carrying out the resource extraction (renting the other factors of production) or entering into a service agreement with a mineral producer to carry out the extraction.

Governments have other reasons for being concerned with the consequences of extraction, including various economic and environmental effects - externalities - such as dislocation of the local population, Dutch disease, and environmental degradation. All of these are potentially significant but will not be distinguished explicitly in the current analysis.

Alternatives (i) and (ii) have relevance at the margin because any benefit from increasing extraction today is reduced by the cost of forgoing the use of surface rights for some other economic activity or for extracting more reserves later. This view of the resource owner's position suggests an associated pricing issue for the reserves being extracted, related to the decline in value of the asset base relative to the opportunity cost of alternative uses. Prior to extraction, the resource stock has economic value and, if extraction occurs, this economic value is diminished by use. Even after the cessation of extraction and closure of a mine, any residual reserves or surface rights are potentially valuable and may become economic for extraction, as has been the case historically, either because of an increase in the value of the mineral (as output) or with lower extraction costs as a result of the application of new technologies (fracking being an obvious example). Some examples where mines have closed and later reopened are given in Table 2. In many of these cases, the mine closed because prices were too low relative to cost given the quality of the deposit only to be reopened later when prices increased. Likewise, the land or sea in which the mineral is located is valuable and this value may be reduced by extraction of the resource. It is the value of reserves and the scarce resources that contain those reserves which define the total value to any resource owner, government included.

\footnotetext{
${ }^{12}$ Selling part of the country is generally not an option for a government, in contrast to private ownership.
} 


\section{Profit-sharing, royalties and social efficiency: the case of certainty and complete informa- tion}

In this section we begin the formal analysis by considering the benchmark situation in which there is no uncertainty and contracting parties have complete information. We demonstrate in this context the proposition that a profitsharing arrangement will generally not be sufficient to insure that a social optimum will be implemented, and that to achieve this objective a royalty is required. The importance of the divergence between the incentives facing resource owners and producers, and the implications for decentralizing the socially efficient outcome will be made clear. The subsequent introduction of uncertainty as well as incomplete and asymmetric information will generalise the results but will not alter the basic conclusion or affect the validity of the underlying principles.

In this contracting situation, the principal is a resource owner (referred to now as the government) and the agent is a resource-extracting firm. The government evaluates the contract according to the payment it receives from the firm and its residual valuation of the property, including reserves, after extraction. The firm seeks to maximize its profit net of the payment made to the government. Extraction, if it occurs, takes place in a single period following the contract agreement.

Let $H(x)$ be the payment made by the firm to the government if a quantity $x$ is extracted. Let $R$ be the initial stock of reserves and $\varphi(R-x)$ the government's residual valuation which will depend on the remaining reserves, $R-x$, both directly and also indirectly through the impact of extraction on the quality of the surrounding property (land or sea). We assume that $\varphi^{\prime}(\cdot)>0$ and $\varphi^{\prime \prime}(\cdot)<0$.

The government's objective function (for a given level of extraction) is the sum of resource revenues and the value of remaining reserves:

$$
W(x, R ; H, \varphi)=H(x)+\varphi(R-x)
$$

For convenience, throughout the paper we will often denote residual reserves $(R-x)$ by $\Delta$.

The firm extracts a quantity $x(0 \leq x \leq R)$ which for simplicity will denote both the quantity of reserves extracted and also the quantity of the resource above ground (oil pumped from a well). The production $\operatorname{cost} C$ rises 
directly with this quantity and also indirectly through the loss of pressure, or increasing depth in the case of minerals, captured in the term $\Delta$ :

$$
C=C(x, \Delta), C_{x}^{\prime}>0, C_{\Delta}^{\prime}<0 .
$$

where subscripts indicate partial derivatives and the dependence of $C$ on input prices has been suppressed. The cost function is assumed to be convex in $x$ and we will assume throughout the paper that $C_{x}^{\prime} \rightarrow+\infty$ as $x \rightarrow R$ (equivalently, $C_{\Delta}^{\prime} \rightarrow-\infty$ as $\Delta \rightarrow 0$ ).

Suppose that the government uses the royalty $\rho(x)$ expressed as the total amount that the firm that extracted $x$ owes to the government. Denote by

$$
\pi(R, x)=p x-C(x, \Delta)-\rho(x)
$$

the profit after the royalty where $p$ is the value of output (extracted ore or raw oil). In addition to the royalty, the government uses the profit share $\beta(\pi)$ which is defined as the total payment that the firm whose profit after royalty is $\pi$ owes to the government. The firm maximizes its profit net of the resource payment:

$$
\pi^{*}(R, x)=\pi(R, x)-\beta(\pi(R, x)),
$$

under the constraint that the profit is non-negative. We also introduce notation

$$
\pi_{\pi}(R, x)=p x-C(x, \Delta)
$$

for the profit before payments to the government.

Provided that the government uses the royalty $\rho(x)$ and the profit share $\beta(\pi)$ for the firm's contract, the total tax revenue $H(x, R)=\rho(x)+\beta(\pi)$. The socially efficient outcome would be achieved if the government owned and operated the firm, in which case its payment would be equal to the profit:

$$
H(x, R)=p x-C(x, \Delta)
$$

Maximizing social welfare would necessitate that

$$
W_{x}^{\prime}=H_{x}^{\prime}-\varphi^{\prime}=p-C_{x}^{\prime}+C_{\Delta}^{\prime}-\varphi^{\prime}=0
$$

This first-order condition shows that the socially efficient level of extraction $\tilde{x}$ must satisfy:

$$
p-C_{x}^{\prime}=-C_{\Delta}^{\prime}+\varphi^{\prime} .
$$


The terms on the right hand side of (??) show that in contrast to the usual efficiency condition, it is necessary to take account of two stock effects at the margin: (a) the effect of declining pressure on the cost of extraction; and (b) the change in the residual value of the property.

On the other hand, if the quantity decision is made by the firm seeking to maximize $\pi^{*}(\cdot)$ given the payment schedule, then (since $\beta(\cdot)$ is monotone) the necessary condition is

$$
\pi_{x}^{* \prime}=p-C_{x}^{\prime}+C_{\Delta}^{\prime}-H_{x}^{\prime}=0 .
$$

This first-order condition shows that the firm's optimal level of extraction $x^{*}$ must satisfy:

$$
p-C_{x}^{\prime}=-C_{\Delta}^{\prime}+H_{x}^{\prime} .
$$

If the government allows the profit-maximizing firm to operate in a decentralized fashion, subject only to the payment function $H(x, R)$, the firm will take account of the stock effect on the cost of extraction, but not - except indirectly through the payment $H$ - the residual stock value. This results from the fact that the resource producer has no right to the residual value of the property once extraction ceases or the contract expires.

Comparing (??) and (??), it is clear that:

$$
\tilde{x}=x^{*} \text { if and only if } H_{x}^{\prime}=\varphi^{\prime}
$$

Thus, the firm will reproduce the government's desired outcome if and only if the marginal payment by the firm is always equal to the marginal value of the stock of reserves. In other words, the marginal payment by the firm should equal the shadow price of reserves.

We can therefore state:

Theorem 1 Suppose that $\tilde{x}$ is the socially efficient extraction level and $x^{*}$ is the firm's profit-maximizing extraction level when both the government and the extracting firm can observe or predict accurately the market price and the level of reserves. Then $\tilde{x}=x^{*}$ if and only if the marginal payment by the firm is equal to the marginal value of residual reserves; i.e., $H_{x}^{\prime}=\varphi^{\prime}$.

From Theorem ?? it follows that optimal marginal payment $H_{x}^{\prime}$ will be zero if and only if marginal extraction has no effect on the stock value. This is the first example of a recurrent theme: the argument for having a royalty as part of the optimal payment scheme is tied to the marginal social cost of 
extraction. Unless this marginal social cost is zero, a payment is required on a per unit basis. We return later to a consideration of the factors that will determine this outcome.

The preceding analysis was focused on the incentives necessary for the firm to behave according to the government's preferences. In principle, if the government has full information and there is no uncertainty, then it can determine its optimal extraction profile, enforce it, and capture any surplus as a lump-sum payment. The enforcement could be achieved in a decentralized manner using a delta function that imposes an arbitrarily high payment for anything other than the desired quantity level. However, governments rarely if ever dictate extraction profiles and do not use lump-sum systems exclusively. Instead, governments rely on price signals to indicate the marginal value of lost reserves via the use of royalties.

Suppose now that the payment by the firm had been specified as a pure profit share; i.e., if

$$
H(x, R)=\beta(p x-C(x, \Delta))
$$

and therefore $\pi=\pi_{\pi}$.

The necessary condition for the firm's optimization would then be (1$\left.\beta^{\prime}(\pi(x, R))\right) \pi_{x}^{\prime}=0$ which implies:

$$
p-C_{x}^{\prime}=-C_{\Delta}^{\prime}
$$

Comparing (??) and (??), the firm's optimal choice under the profit-sharing arrangement will reproduce the socially efficient quantity of extraction if and only if $\varphi^{\prime} \equiv 0$; i.e., if and only if, at the margin, residual reserves have no value, imputed or otherwise. The latter condition means that the value of reserves for the entire future is zero because the residual value of the asset is independent of the amount extracted. In other words, a profit share will not be optimal, at least not by itself, if the mine has some residual value at the margin so that, economically speaking, reserves are not in excess supply forever.

\section{Linear payment schemes}

Resource-specific payments made by extracting firms are frequently based on a combination of a fixed ad valorem royalty rate and a fixed profit share (perhaps the generally applicable profits tax), with royalty payments deductible from pre-tax profits (see Table 1). We can extend the previous analysis by 
examining the principal-agent problem when the payment function $H$ is specified to be of this type but restricted to being linear in the firm's revenue and its profit net of the royalty payment. With the form of the payment function thus specified and the firm responding with its choice of extraction level, the government will want to choose the parameters optimally, subject to a participation constraint that leaves the firm with a non-negative payoff. Again, by assumption, there is no uncertainty or informational problem to address.

When the payment scheme is linear as specified above, then

$$
H=\rho p x+\beta[(1-\rho) p x-C(x, \Delta)]+K,
$$

where here $\beta$ is the fractional share of profit (or a 'Brown tax'), $\rho$ is the royalty rate, and $K$ is a lump-sum payment.

It is straightforward to show that in this case the optimal royalty rate is the marginal social value of reserves. In other words, it is this royalty rate that provides the requisite incentive for the firm to behave in a socially efficient manner.

Theorem 2 Suppose that $\tilde{x}$ is the socially efficient extraction level and $x^{*}$ is the firm's profit-maximizing extraction level when both the government and the extracting firm can observe or predict accurately the market price and the level of reserves. If the payment scheme is restricted to be a linear combination of an ad valorem royalty and a fixed profit share, then the extraction level will be socially efficient $\left(\tilde{x}=x^{*}\right)$ if and only if the royalty rate is

$$
\rho=\varphi^{\prime}(R-\tilde{x}) / p
$$

Proof:

The firm's objective function is:

$$
\pi^{*}=(1-\beta)[(1-\rho) p x-C(x, \Delta)]-K
$$

and the government's social welfare function is

$$
W(x, R ; H, \varphi)=\rho p x+\beta[(1-\rho) p x-C(x, \Delta)]+K+\varphi(\Delta) .
$$

Faced with the linear payment function, the firm will choose $x^{*}$ to maximize $\pi^{*}$. Provided the firm extracts a positive amount of the resource, $x^{*}$ will satisfy the first-order condition:

$$
\pi_{x}^{* \prime}=(1-\beta)\left[(1-\rho) p-C_{x}^{\prime}+C_{\Delta}^{\prime}\right]=0
$$


i.e., $x^{*}$ satisfies

$$
(1-\rho) p-C_{x}^{\prime}=-C_{\Delta}^{\prime} .
$$

Of the three payment parameters, only the royalty rate $\rho$ affects the firm's decision at the margin. The quantity extracted $x^{*}$ will depend only on $\rho$ : $x^{*}=x^{*}(\rho)$.

Knowing how the firm will respond to the payment parameters, the government wants to choose these parameters in order to maximize $W$ subject to the participation constraint,

$$
\pi^{*}=\pi_{\pi}-H(x, R) \geq \bar{\pi}
$$

where $\bar{\pi}$ represents the firm's best profit alternative.

The participation constraint will be binding at the optimum and therefore the social welfare subject to the firm's first-order condition can be expressed as:

$$
W(H, \varphi)=\pi_{\pi}-\bar{\pi}+\varphi\left(R-x^{*}\right)=p x^{*}-C\left(x^{*}, R-x^{*}\right)-\bar{\pi}+\varphi\left(R-x^{*}\right)
$$

where $x^{*}$ is a function of $\rho$. From the first-order condition it follows that the government will want the firm to choose its extraction quantity $x^{*}=\tilde{x}$ such that

$$
p-C_{x}^{\prime}\left(x^{*}, R-x^{*}\right)=-C_{\Delta}^{\prime}\left(x^{*}, R-x^{*}\right)+\varphi^{\prime}\left(R-x^{*}\right),
$$

where we used a simple fact that $x^{*}$ is a monotone function of $\rho$. Note that condition (??) is the counterpart of condition (??) for the social optimum.

Comparing equations (??) and (??), the government will maximize social welfare by choosing the royalty rate $\rho$ such that $\rho p=\varphi^{\prime}\left(R-x^{*}\right)$; i.e.,

$$
\rho=\frac{\varphi^{\prime}\left(R-x^{*}\right)}{p}
$$

Q.E.D.

Theorem ?? establishes that in the optimal linear payment scheme, the royalty rate will be set equal to the marginal social value of reserves. It follows trivially that the optimal royalty will be zero if $\varphi^{\prime}=0$; that is, if there is no social consequence (or opportunity cost) to extraction other than the resulting revenue. 
So the value of $\varphi$, and more particularly its derivative $\varphi^{\prime}$, is of the essence in concluding whether or not there is a material justification for including royalties among the set of payment parameters.

As discussed above in Section ??, there are a number of factors contributing to the marginal social cost of extracting the resource. Most fundamentally, marginal social cost will include a measure of the reduction in the value of the asset (the stock of the resource) arising from its depletion. This is the user cost of capital (Scott 1967) with resource depletion as the counterpart of capital depreciation (Hall and Jorgenson 1967). Capital depreciation in the Hall-Jorgenson model is exogenous whereas depreciation (depletion) in natural resource models is endogenous; the resource owner (not the producer) must determine the rate at which the value of reserves is depleted. This is analogous to a leasing company determining the charge (including depreciation) to impose for use of the leasing company's machinery or to a distributor determining the charge per unit of selling from inventory. ${ }^{13}$ Regardless of how the stock value is determined, if the value is reduced with use - in this case, if the value of reserves is reduced with extraction - then a marginal charge is necessary even if that stock is not completely exhausted.

\section{Royalties as the competitive equilibrium price of reserves}

Closely related to the preceding analysis is an interpretation of the royalty as the competitive equilibrium price in the market for extractable reserves. The demand side of the market reflects the extracting firm's response to the parameters of its operating environment; in particular, the payment function set by the government. The supply of reserves is determined by the government in conjunction with this payment function.

The firm's demand for reserves, $x^{*}$ is the solution to its profit maximization problem, given the payment function $H(\cdot, \cdot)$; i.e., $x^{*}$ is the solution to the first-order condition (??) which we will rewrite as

$$
H_{x}^{\prime}=p-C_{x}^{\prime}+C_{\Delta}^{\prime} .
$$

\footnotetext{
${ }^{13}$ The inventory reduction problem illustrates the inconsistent treatment of natural resources. Few would claim that an excess inventory of automobiles at the end of the model year implies that the automobile producer should sell infra-marginal inventory at a zero price or that automobiles are in excess supply because the shadow price of cars at the end of the model year is zero. Prices might be reduced but there are good economic efficiency reasons to believe that automobile producers are not high-grading or prematurely curtailing sales because of excess supply at the end of the model year.
} 
The right-hand side of equation (??) is the demand for reserves as an input into the production process. Viewed from a production function approach, via the dual of the cost function, the value of the marginal product of reserves would be zero if the left-hand side of (??) is zero.

The supply of reserves by the government, $\tilde{x}$ is the solution to its welfare maximization problem; i.e., $\tilde{x}$ is the solution to the first-order condition

$$
W_{x}^{\prime}=H_{x}^{\prime}-\varphi^{\prime}=0
$$

which we rearrange as

$$
H_{x}^{\prime}=\varphi^{\prime}
$$

The equilibrium condition for this market for reserves is thus

$$
H_{x}^{\prime}=p-C_{x}^{\prime}+C_{\Delta}^{\prime}=\varphi^{\prime}
$$

which reveals the marginal payment $H_{x}^{\prime}$ as the price of reserves.

If $H$ is restricted to be a linear function of a profit share and a royalty, as above, then

$$
H_{x}^{\prime}=\rho p=\varphi^{\prime}
$$

i.e., the royalty $\rho p$ is the implicit market price (or shadow price) of reserves.

Natural resources are a stock and if the stock is scarce in an economic sense then it will have a non-zero shadow price. The royalty is that shadow price. Economic scarcity of a resource is not the same thing as physical exhaustion. If the efficient royalty is zero, then natural resources are not scarce; equivalently, they are in excess supply.

\section{Uncertainty and asymmetric information}

We now turn to situations in which there is uncertainty about one or more parameters and the government and mining firm are not equally informed. Clearly, there are many ways in which uncertainty and related informational asymmetries can enter the extraction decision and contracting problem. We focus on two sources: uncertainty about the quantity of reserves $(R)$ in the mine, and uncertainty about the value $(p)$ of the extracted product. In the first case we examine, the firm will know $R$ but the government will have only a belief characterized by a probability distribution over $R$. In the two remaining cases considered, the uncertainty and informational asymmetry 
regarding reserves will be compounded by price uncertainty, first for the government only and then for both the firm and the government.

In all cases, the government is tasked with framing a contract in which the payment by the firm comprises a nonlinear royalty payment $\rho(\cdot)$ which is a function of the amount of ore extracted, and a nonlinear profit share payment $\beta(\cdot)$ which is a function of the firm's profit net of the royalty payment. We assume that the royalty schedule is differentiable in extraction with derivative $\rho^{\prime}$ and the profit share is differentiable in profit with derivative $\beta^{\prime}$.

The government's objective function is the social welfare

$$
\begin{aligned}
W(x, R ; \rho(\cdot), \beta(\cdot)) & =H(x, R)+\varphi(R-x) \\
& =\rho(x)+\beta\left(\pi_{\pi}(x, R)-\rho(x)\right)+\varphi(R-x) .
\end{aligned}
$$

Case (a) Suppose the only uncertainty pertains to the government's knowledge of $R$.

Let the government's a priori information about $R$ be described by the probability density function $f_{R}(R)$. The government must choose the payment functions $\rho(\cdot)$ and $\beta(\cdot)$ before the firm makes its extraction decision. The firm's profit-maximizing extraction level will be a function $x^{*}=x^{*}(R ; \rho(\cdot), \beta(\cdot))$.

The government is seeking to maximise expected welfare,

$$
\begin{aligned}
& E\left[W\left(x^{*}(R ; \rho(\cdot), \beta(\cdot)), R ; \rho(\cdot), \beta(\cdot)\right)\right] \\
& =\int W\left(x^{*}(R ; \rho(\cdot), \beta(\cdot)), R ; \rho(\cdot), \beta(\cdot)\right) f_{R}(R) d R
\end{aligned}
$$

The sequential timing of the problem can be characterized as follows.

- Period 1: The government sets the contract terms based on maximizing expected welfare.

- Period 2: The firm discovers the actual amount of reserves.

- Period 3: The firm makes its extraction decision (as well as the market participation decision) based on the payment schedule set by the government and the amount of discovered reserves.

- Period 4: The firm reports the reserves, profits and extraction, and pays the royalty and profit share to the extent applicable.

We can now establish the following result. 
Theorem 3 Suppose that both the government and the extracting firm can observe or predict accurately the market price but only the firm observes the level of reserves. If the government can charge the firm a nonlinear royalty and a nonlinear profit share then the optimal payment schedules are as follows:

(i) Royalty:

$$
\rho(x)=\int_{\tilde{x}(\underline{R})}^{x} \varphi^{\prime}\left(\tilde{x}^{-1}(z)-z\right) d z .
$$

(ii) Profit share:

$$
\beta(\pi)=\left\{\begin{array}{l}
\pi, \text { if } p \tilde{x}(\underline{R})-C(\tilde{x}(\underline{R}), \underline{R}-\tilde{x}(\underline{R}))-\rho(\tilde{x}(\underline{R}))<\pi, \\
p \tilde{x}(\underline{R})-C(\tilde{x}(\underline{R}), \underline{R}-\tilde{x}(\underline{R}))-\rho(\tilde{x}(\underline{R})), \text { otherwise. }
\end{array}\right.
$$

where $\tilde{x}(R)$ is the efficient extraction level consistent with reserves $R$, satisfying

$$
p-C_{x}^{\prime}(\widetilde{x}, R)-\varphi^{\prime}(R-\widetilde{x})=0
$$

and $\underline{R}$ is a minimum quantity of reserves below which the resource owner will not allow any extraction.

Proof:

Throughout the proof we use notation $C(x, R)$ instead of $C(x, \Delta)$ for the cost of extraction by the firm to simplify algebra. The firm's optimal extraction is characterised by the first-order condition

$$
\left(p-C_{x}^{\prime}\left(x^{*}, R\right)-\rho^{\prime}\left(x^{*}\right)\right)\left(1-\beta^{\prime}\left(\pi\left(x^{*}, R\right)\right)\right)=0
$$

and the participation constraint

$$
\pi\left(x^{*}, R\right)-\beta\left(\pi\left(x^{*}, R\right)\right) \geq 0
$$

This is a constrained nonlinear optimal control problem. In general, such problems do not have closed-form solutions. We now show how the problem can be solved for this particular case and find its closed-form solution.

Because the social welfare function is linear in the profit share and the profit share does not create marginal incentives, whenever the firm extracts a non-zero amount the optimal solution for the government is to set $\beta\left(\pi\left(x^{*}, R\right)\right)=$ $\pi\left(x^{*}, R\right)$. The structure of the profit share is therefore:

$$
\beta(\pi)= \begin{cases}\underline{\pi}, & \text { if } \pi \leq \underline{\pi} \\ \pi, & \text { if } \pi>\underline{\pi}\end{cases}
$$


In this structure, the government sets an after-royalty profit threshold $\underline{\pi}$. The firm will extract only if it can exceed this threshold; in effect, the government does not allow development of the deposit otherwise.

Substituting this expression into the welfare function, we find that once it is optimized with respect to the profit share it takes the form

$$
W(R, x ; \rho(\cdot), \beta(\cdot))=\left\{\begin{array}{c}
p x-C(x, R)+\varphi(R-x), \\
\text { if } p x-C(x, R)-\rho(x)>\underline{\pi}, \\
\varphi(R), \quad \text { otherwise }
\end{array}\right.
$$

In other words, the government is interested in maximizing the before payment profit of the firm corrected for the value of the remaining reserves, whenever the after-royalty profit exceeds a particular threshold.

In mathematical form, if $x^{*}(R, \rho(\cdot))$ is the optimal level of extraction for the firm responding to the royalty schedule, then the expected ex ante welfare can be written as

$$
\begin{aligned}
& E\left[W\left(x^{*}(R, \rho(\cdot)), R ; \rho(\cdot), \beta(\cdot)\right)\right] \\
& =\int_{\pi\left(x^{*}(R, \rho(\cdot)), R\right) \geq \underline{\pi}}\left[p x^{*}(R, \rho(\cdot))-C\left(x^{*}(R, \rho(\cdot)), R\right)\right. \\
& \left.+\varphi\left(R-x^{*}(R, \rho(\cdot))\right)\right] f_{R}(R) d R \\
& +\int_{\pi\left(x^{*}(R, \rho(\cdot)), R\right) \geq \underline{\pi}} \varphi(R) f_{R}(R) d R .
\end{aligned}
$$

The government's problem now is to set the optimal royalty schedule $\rho(\cdot)$ and the threshold $\underline{\pi}$ to maximize the expected welfare. This can be solved in two steps.

\section{Step 1}

Consider the first term in $E\left[W\left(x^{*}(R, \rho(\cdot)), R ; \rho(\cdot), \beta(\cdot)\right)\right]$ :

$$
\begin{aligned}
\int_{\pi\left(x^{*}(R, \rho(\cdot)), R\right) \geq \underline{\pi}}\left[p x^{*}(R, \rho(\cdot))-\right. & C\left(x^{*}(R, \rho(\cdot)), R\right) \\
& \left.+\varphi\left(R-x^{*}(R, \rho(\cdot))\right)\right] f_{R}(R) d R .
\end{aligned}
$$

Note that the royalty schedule enters this expression only implicitly through the extraction level $x^{*}$. Therefore, the royalty needs to be selected such that 
the solution to the problem of maximizing the social gain from extraction (payment adjusted for the social value of reserves) coincides with the solution to the firm's problem of maximizing profit net of the royalty payment.

The social value is maximized at $\tilde{x}$ such that

$$
p-C_{x}^{\prime}(\tilde{x}, R)-\varphi^{\prime}(R-\tilde{x})=0
$$

We can denote the solution of this equation $\tilde{x}(R)$, given that the social welfare function is fixed. It follows from differentiation of equation (??) that if the cost function is convex and the social valuation of reserves is concave, then $\tilde{x}(R)$ is increasing in $R$. The profit net of royalty is maximized at $x^{*}$ such that

$$
p-C_{x}^{\prime}\left(x^{*}, R\right)-\rho^{\prime}\left(x^{*}\right)=0 .
$$

The quantity of extraction with the royalty corresponds to the maximum of social welfare if $x^{*}=\tilde{x}$ for each level of reserves. Comparing the two first-order conditions, we see that this occurs when

$$
\rho^{\prime}(x)=\varphi^{\prime}\left(\tilde{x}^{-1}(x)-x\right) .
$$

\section{Step 2}

By construction $x^{*}(R, \rho(\cdot))=\tilde{x}(R)$, which maximizes the sum of pre-payment profit and the social value of reserves. We also note that by the envelope theorem

$$
\frac{d \pi\left(x^{*}(R, \rho(\cdot)), R\right)}{d R}=\frac{\partial \pi\left(x^{*}(R, \rho(\cdot)), R\right)}{\partial R}>0,
$$

because $\tilde{x}(R)$ also maximizes the profit after royalty. As a result, the optimal after-royalty profit is a strictly increasing function of $R$. Now given that $\pi\left(x^{*}(R, \rho(\cdot)), R\right)=\pi(\tilde{x}(R), R)$ and it is strictly increasing in $R$, we can invert $\pi(\tilde{x}(R), R)$ as a function of $R$. Denote by $R=\pi^{-1}(\underline{\pi})$ the solution of $\pi(\tilde{x}(R), R)=\underline{\pi}$. The ex ante social welfare can now be expressed as a function of a single parameter $\underline{\pi}$, the threshold profit from extraction above which the government allows extraction:

$$
\begin{aligned}
& E\left[W\left(x^{*}(R, \rho(\cdot)), R ; \rho(\cdot), \beta(\cdot)\right)\right] \\
& =\int_{R \geq \pi^{-1}(\underline{\pi})}[p \tilde{x}(R)-C(\tilde{x}(R), R)+\varphi(R-\tilde{x}(R))] f_{R}(R) d R \\
& +\int_{R<\pi^{-1}(\underline{\pi})} \varphi(R) f_{R}(R) d R .
\end{aligned}
$$


We note that the optimal profit threshold that solves the first-order condition

$$
\frac{\partial E\left[W\left(x^{*}(R, \rho(\cdot)), R ; \rho(\cdot), \beta(\cdot)\right)\right]}{\partial \underline{\pi}}=0,
$$

corresponds to the minimal amount of reserves in the deposit at which the social welfare loss from reducing reserves will become smaller than the social gain from government revenue. Denote by $\underline{R}=\pi^{-1}(\underline{\pi})$ where $\underline{\pi}$ solves the first-order condition above.

Explicitly taking the derivatives we find that

$$
\begin{aligned}
\frac{\partial E\left[W\left(x^{*}(R, \rho(\cdot)), R ; \rho(\cdot), \beta(\cdot)\right)\right]}{\partial \underline{\pi}} & =-(p \tilde{x}(\underline{R})-C(\tilde{x}(\underline{R}), \underline{R}) \\
& +\varphi(\underline{R}-\tilde{x}(\underline{R})))\left(\frac{\partial \pi(\tilde{x}(\underline{R}), \underline{R})}{\partial R}\right)^{-1} \\
& +\varphi(\underline{R})\left(\frac{\partial \pi(\tilde{x}(\underline{R}), \underline{R})}{\partial R}\right)^{-1}=0
\end{aligned}
$$

The solution can be expressed as

$$
p \tilde{x}(\underline{R})-C(\tilde{x}(\underline{R}), \underline{R})=\varphi(\underline{R})-\varphi(\underline{R}-\tilde{x}(\underline{R}))
$$

On the left-hand side of this expression there is a social gain (firm's profit before payments) and on the right-hand side there is a social cost (reduction in the social value of the reserves).

The full payment schedule takes the following form:

(i) Royalty

$$
\rho(x)=\int_{\tilde{x}(\underline{R})}^{x} \varphi^{\prime}\left(\tilde{x}^{-1}(z)-z\right) d z
$$

(ii) Profit share

$$
\beta(\pi)=\left\{\begin{array}{l}
p \tilde{x}(\underline{R})-C(\tilde{x}(\underline{R}), \underline{R})-\rho(\tilde{x}(\underline{R})), \\
\quad \text { if } \pi<p \tilde{x}(\underline{R})-C(\tilde{x}(\underline{R}), \underline{R})-\rho(\tilde{x}(\underline{R})), \\
\pi, \quad \text { otherwise. }
\end{array}\right.
$$

Q.E.D.

As in the perfect certainty case, the royalty depends on the marginal opportunity cost of depletion. The royalty amount may vary with extraction 
(or more specifically, with the level of reserves discovered). One special case is where the marginal reduction in the value of reserves is constant $\left(\varphi^{\prime \prime}=0\right)$ over the relevant extraction range. In this case, the royalty would be constant. In other cases, the royalty payment will depend on cumulative extraction and the per unit amount will vary for each level of extraction. In effect, the government, ex post, is able to price discriminate on a per unit basis and is able to capture the infra-marginal value. The result also provides some support for the use of geological factors such as reserves or cumulative extraction in practice; for example, the royalties used in the Netherlands, Nigeria, and Kazakhstan.

The profit share is completely one-sided in favor of the state. After reserves are determined, the government knows everything needed to extract the entire surplus from the producer and can do so efficiently with a simple fixed payment or service contract model.

We also see that the government may impose a minimum reserve requirement where reserves below the level specified will not be sufficient for the recovery of the fixed cost of devoting the reserves to extraction.

Case (b) Suppose now that there is also uncertainty about the value of the extracted mineral when the government is determining the payment regime but that subsequently the price is known to the firm when it makes its extraction decision. We assume that this price uncertainty is independent from uncertainty about reserves.

The sequential timing of decisions is similar to that described for the previous case where only reserves are uncertain for the government:

- Period 1: The government sets the contract terms based on maximizing expected welfare.

- Period 2: The firm discovers the actual quantity of reserves and the market price of the resource.

- Period 3: The firm makes the extraction decision (as well as the market participation decision) based on the payment schedule, price and discovered reserves.

- Period 4: The firm reports the price and discovered reserves to the government and pays the royalty and profit share to the government based on the contract terms. 
In this case, the government is assumed to have independent probability distributions over $R$ and $p$, with densities $f_{R}$ and $f_{p}$. Provided that the profit-maximizing extraction level is a function $x=x(p, R ; \rho(\cdot), \beta(\cdot))$, the government will want to choose payment schedules $\rho(\cdot)$ and $\beta(\cdot)$ to maximise expected welfare:

$$
\begin{aligned}
& E[W(x(p, R ; \rho(\cdot), \beta(\cdot)), R ; \rho(\cdot), \beta(\cdot))] \\
& =\int W(x(p, R ; \rho(\cdot), \beta(\cdot)), R ; \rho(\cdot), \beta(\cdot)) f_{p}(p) f_{R}(R) d p d R .
\end{aligned}
$$

We can establish the following result.

Theorem 4 Suppose that the government must set the payment schedule while uncertain about both the stock of reserves and the mineral price whereas the extracting firm can observe or predict accurately these values when making its extraction decision. If the government can charge the firm a nonlinear royalty and a nonlinear profit share then the optimal payment schedules are as follows:

(i) Royalty

$$
\rho(x)=\int_{p} \int_{\tilde{x}(\underline{R})}^{x} \varphi^{\prime}\left(\tilde{x}^{-1}(p, z)-z\right) f_{p}(p) d p d z .
$$

(ii) Profit share

$$
\beta(\pi)=\left\{\begin{array}{l}
\underline{\pi}(p), \quad \text { if } \pi<\underline{\pi}(p) \\
\pi, \quad \text { otherwise }
\end{array}\right.
$$

where $\tilde{x}(p, R)$ solves

$$
p-C_{x}^{\prime}(\tilde{x}, R-\tilde{x})-\varphi^{\prime}(R-\tilde{x})=0 .
$$

and

$$
\underline{\pi}(p)=p \tilde{x}(p, \underline{R}(p))-C(\tilde{x}(p, \underline{R}(p)), \underline{R}(p))-\rho(\tilde{x}(p, \underline{R}(p))
$$

for

$$
p \tilde{x}(p, \underline{R}(p))-C(\tilde{x}(p, \underline{R}(p)), \underline{R}(p))=\varphi(\underline{R}(p))-\varphi(\underline{R}(p)-\tilde{x}(p, \underline{R}(p))) .
$$

Proof:

The solution of the firm's optimal decision problem is characterized by the first-order condition along with the participation constraint:

$$
\left(p-C_{x}^{\prime}\left(x^{*}, R\right)-\rho^{\prime}\left(x^{*}\right)\right)\left(1-\beta^{\prime}\left(\pi\left(p, x^{*}, R\right)\right)\right)=0,
$$


and

$$
\pi\left(p, x^{*}, R\right)-\beta\left(\pi\left(p, x^{*}, R\right)\right) \geq 0 .
$$

To solve the problem we use the standard calculus of variations. First note that, because social welfare is linear in the profit share and the profit share does not create distortions, whenever the firm extracts a non-zero amount, the optimal solution for the government is to set $\beta(\pi)=\pi$. Thus, the structure of the profit share is the following:

$$
\beta(\pi)=\left\{\begin{array}{l}
\underline{\pi}(p), \quad \text { if } \pi \leq \underline{\pi}(p), \\
\pi, \quad \text { if } \pi>\underline{\pi}(p) .
\end{array}\right.
$$

This expression resembles the structure when there is no price uncertainty, but the thresholds are now allowed to depend on the price.

Substituting this expression into the welfare function, we obtain a welfare function optimized with respect to the profit share:

$$
W(p, x, R ; \rho(\cdot), \beta(\cdot))=p x-C(x, R)+\varphi(R-x),
$$

if $p x-C(x, R)-\rho(x)>\underline{\pi}$ and the welfare is $\varphi(R)$ otherwise (where $\underline{\pi}$ is the profit threshold to be determined later).

In mathematical form, if $x^{*}(p, R, \rho(\cdot))$ is the optimal solution of the firm responding to the royalty schedule, then the expected ex ante welfare can be written

$$
\begin{aligned}
& E\left[W\left(p, x^{*}(p, R, \rho(\cdot)), R ; \rho(\cdot), \beta(\cdot)\right)\right] \\
& =\int_{\pi\left(p, x^{*}(p, R, \rho(\cdot)), R\right)>\underline{\pi}}\left[p x^{*}(p, R, \rho(\cdot))-C\left(x^{*}(p, R, \rho(\cdot)), R\right)\right. \\
& \left.+\quad \varphi\left(R-x^{*}(p, R, \rho(\cdot))\right)\right] f_{p}(p) f_{R}(R) d p d R \\
& +\int_{\pi\left(p, x^{*}(p, R, \rho(\cdot)), R\right) \leq \underline{\pi}} \varphi(R) f_{p}(p) f_{R}(R) d p d R .
\end{aligned}
$$

The problem of the government now is to set the optimal royalty schedule $\rho(\cdot)$ and the threshold $\underline{\pi}$ to maximize the welfare:

$$
\begin{aligned}
& \int_{\pi\left(p, x^{*}(R, \rho(\cdot)), R\right) \geq \underline{\pi}} {\left[p x^{*}(p, R, \rho(\cdot))-C\left(x^{*}(p, R, \rho(\cdot)), R\right)\right.} \\
&\left.+\varphi\left(R-x^{*}(p, R, \rho(\cdot))\right)\right] f_{p}(p) f_{R}(R) d R
\end{aligned}
$$


We note that the royalty schedule enters this expression only implicitly through the extraction level $x^{*}$. Therefore, we can first find the expected welfare-maximizing exraction level and then determine the royalty schedule compatible with such extraction. As a result, using the envelope theorem we note that

$$
\begin{aligned}
& 0=\int_{\pi\left(p, x^{*}(p, R, \rho(\cdot)), R\right) \geq \underline{\pi}}\left[p-C_{x}^{\prime}\left(x^{*}(p, R, \rho(\cdot)), R\right)\right. \\
& \left.-\varphi^{\prime}\left(R-x^{*}(p, R, \rho(\cdot))\right)\right] f_{p}(p) f_{R}(R) d R \\
& =\int_{\pi\left(p, x^{*}(p, R, \rho(\cdot)), R\right) \geq \underline{\pi}}\left[p-C_{x}^{\prime}\left(x^{*}(p, R, \rho(\cdot)), R\right)\right] f_{p}(p) f_{R}(R) d R d p \\
& -\int_{\pi\left(p, x^{*}(p, R, \rho(\cdot)), R\right) \geq \underline{\pi}}\left(\int_{p} \varphi^{\prime}\left(R-x^{*}(p, R, \rho(\cdot))\right) f_{p}(p) d p\right) f_{R}(R) d R
\end{aligned}
$$

The social value of profit adjusted for the loss of reserves is maximized at $\tilde{x}$ such that

$$
p-C_{x}^{\prime}(\tilde{x}, R)-\varphi^{\prime}(R-\tilde{x})=0 .
$$

Suppose that $\tilde{x}(p, R)$ is the solution to this equation and $\tilde{x}^{-1}(p, x)$ is a solution of equation $\tilde{x}(p, R)=x$ for a given price $p$. Combining this with (??) we have the optimal royalty rate given by

$$
\rho^{\prime}(x)=\int_{p} \varphi^{\prime}\left(\tilde{x}^{-1}(p, x)-x\right) f_{p}(p) d p .
$$

To find the threshold profit $\underline{\pi}$ determining the structure of the profit share we take equation

$$
p \tilde{x}(p, R)-C(\tilde{x}(p, R), R)=\varphi(R)-\varphi(R-\tilde{x}(p, R))
$$

which balances profit from extraction (before payments) against the social cost of the extraction, and solve this equation for $R$ for each $p$ and obtain the function $\underline{R}(p)$. We obtain the profit corresponding to the extraction threshold as a function of price,

$$
\underline{\pi}(p)=p \tilde{x}(p, \underline{R}(p))-C(\tilde{x}(p, \underline{R}(p)), \underline{R}(p))-\rho(\tilde{x}(p, \underline{R}(p)) .
$$

The payment schedules thus take the following form:

(i) Royalty

$$
\rho(x)=\int_{p} \int_{\tilde{x}(\underline{R})}^{x} \varphi^{\prime}\left(\tilde{x}^{-1}(p, z)-z\right) f_{p}(p) d p d z .
$$


(ii) Profit share

$$
\beta(\pi)=\left\{\begin{array}{l}
\underline{\pi}(p), \text { if } \pi \leq \underline{\pi}(p) \\
\pi, \quad \text { otherwise }
\end{array}\right.
$$

Q.E.D.

The optimal royalty has the same general form as when the government is uncertain about reserves only. Once again, the government is able to discriminate in the sense that all infra-marginal opportunity cost is recovered. The recovery of full opportunity cost relative to the certainty case is not complete, however, because the government never knows the price and the infra-marginal values now depend on the government's price distribution.

Profit sharing is again fully in favor of the government because it can force the firm to pay the full amount of reported ex post profit.

Case (c) Suppose that now, in addition to the government's uncertainty about the level of reserves and the price of the extracted mineral, the firm also is exposed to the price uncertainty and must make its extraction decision before the output price is revealed. We demonstrate that in this case the optimal payment schedule does not generally decompose into a profit share and the royalty: the royalty will be taken on the basis of the excessive profit of the firm that is computed using the distribution of market prices. The timing of the new problem will be the following.

- Period 1: The government sets the contract terms based on maximizing expected welfare.

- Period 2: The firm discovers the actual reserve amount.

- Period 3: The firm makes the extraction decision (as well as the market participation decision) based on the contract with the government and the discovered reserve but without knowing the price.

- Period 4: Price uncertainty is realized and the firm pays the royalty and profit share to the government based on the contract terms.

To identify clearly the source of uncertainty, we will use $E_{p}[\cdot]$ to denote the expectation with respect to price uncertainty and $E_{R p}[\cdot]$ the expectation with respect to uncertainty about both price and reserves. We assume, to avoid further complication, that both the government and the firm hold the same probability distribution over prices. 
The expected profit of the firm after payment of the royalty and profit share is

$$
E_{p}\left[\pi^{*}(p, R, x)\right]=E_{p}[p x-C(R, x)-\rho(x)-\beta(\pi(p, R, x))] .
$$

The first-order condition for the firm and ex ante participation constraint for the firm can be written as

$$
E_{p}\left[\left(p-C_{x}^{\prime}\left(x^{*}, R\right)-\rho^{\prime}\left(x^{*}\right)\right)\left(1-\beta^{\prime}\left(\pi\left(p, R, x^{*}\right)\right)\right)\right]=0
$$

and

$$
\pi\left(\bar{p}, R, x^{*}\right)-E_{p}\left[\beta\left(\pi\left(p, R, x^{*}\right)\right)\right] \geq 0,
$$

where $\bar{p}=E_{p}[p]$. If we introduce notation $\bar{\beta}^{\prime}=E_{p}\left[\beta^{\prime}\left(\pi\left(p, R, x^{*}\right)\right)\right]$ then we can rewrite the first order condition as:

$$
\left(\bar{p}-C_{x}^{\prime}\left(x^{*}, R\right)-\rho^{\prime}\left(x^{*}\right)\right)\left(1-\bar{\beta}^{\prime}\right)=\operatorname{cov}_{p}\left(p, \beta^{\prime}\left(\pi\left(p, R, x^{*}\right)\right)\right)
$$

We can compare this with the first-order condition when there was no price uncertainty. If the price were fixed at its average level $\bar{p}$ and the marginal profit share were fixed at its average level, the left-hand side of (??) would equal zero. The effect of the price uncertainty is to cause the marginal profit after royalty to be proportional to the covariance between the price and the marginal profit share, which we expect to be positive.

We note next that the threshold structure for the profit share, established in the cases where there is no price uncertainty for the firm, will no longer apply. For each extraction level, there will be a range of prices for which the profit of the firm will be below any given threshold $\underline{\pi}$ and the firm will not participate.

With this information, the expected social welfare can be written:

$$
E_{R p}[W(x, R ; \rho(\cdot), \beta(\cdot))]=E_{R p}[\rho(x)+\beta(\pi(p, R, x))+\varphi(R-x)] .
$$

The social welfare is strictly increasing in the profit share (all other things being equal). As a result the welfare maximizing profit share will make the participation constraint binding, i.e.

$$
E_{p}\left[\beta\left(\pi\left(p, R, x^{*}\right)\right)\right]=\pi\left(\bar{p}, R, x^{*}\right)
$$

whenever the firm chooses to extract from the deposit. Equation (??) only contains the extraction level $x^{*}$ and the reserves $R$. As a result, for each pair 
of payment schedules $\rho(\cdot)$ and $\beta(\cdot)$ there will exist the reserve level $\underline{R}$ below which the firm decides not to participate. Thus the welfare at the optimum can be rewritten as

$$
\begin{gathered}
E_{R p}\left[W\left(x^{*}, R ; \rho(\cdot), \beta(\cdot)\right)\right] \\
=E_{R}\left[\left(\pi_{\pi}\left(\bar{p}, R, x^{*}\right)+\varphi\left(R-x^{*}\right)\right) \mathbf{1}\{R>\underline{R}\}\right] \\
+E[\varphi(R) \mathbf{1}\{R \leq \underline{R}\}]
\end{gathered}
$$

where $\underline{R}$ is the minimal level of reserves below which the firm does not participate. The social welfare will be maximized at $\tilde{x}(R)$ such that

$$
\bar{p}-C_{x}^{\prime}(\tilde{x}, R)-\varphi^{\prime}(R-\tilde{x})=0 .
$$

Then $\tilde{x}(R)$ will solve the first-order condition of the firm (??) if and only if

$$
\rho^{\prime}\left(x^{*}\right)+\frac{\operatorname{cov}_{p}\left(p, \beta^{\prime}\left(\pi\left(p, R, x^{*}\right)\right)\right)}{1-\bar{\beta}^{\prime}}=\varphi^{\prime}\left(R-x^{*}\right) .
$$

Recall that expected social welfare (??) depends on the reserve threshold $\underline{R}$ below which the firm does not participate. Provided that this threshold is determined by the royalty and the profit share, it can be treated as the choice variable of the government. Taking the derivative of the expected social welfare with respect to $\underline{R}$, we find the minimal extraction level $\underline{R}=\tilde{x}^{-1}(\underline{x})$ such that

$$
\pi_{\pi}\left(\bar{p}, \tilde{x}^{-1}(\underline{x}), \underline{x}\right)=\varphi\left(\tilde{x}^{-1}(\underline{x})\right)-\varphi\left(\tilde{x}^{-1}(\underline{x})-\underline{x}\right),
$$

where $\tilde{x}(\cdot)$ is the welfare-maximizing extraction level from (??).

The optimal royalty therefore can be expressed as

$$
\rho(x)=\int_{\underline{x}}^{x} \varphi^{\prime}\left(\tilde{x}^{-1}(z)-z\right) d z-\int_{\underline{x}}^{x} \frac{\operatorname{cov}_{p}\left(p, \beta^{\prime}\left(\pi\left(p, \tilde{x}^{-1}(z), z\right)\right)\right)}{1-\bar{\beta}^{\prime}} d z .
$$

The efficient royalty is now dependent on the marginal value of depletion adjusted for the covariance between price and the profit sharing rate.

To characterize the optimal profit share, we note that it should prohibit participation of firms that would extract less than $\underline{x}$ (given that it is socially optimal not to extract if reserves are too low). The profit share should also satisfy the participation constraint for any (optimal) extraction level above $\underline{x}$. Thus:

$$
E_{p}\left[\beta\left(p x-C\left(x, \tilde{x}^{-1}(x)\right)-\rho(x)\right)\right]=\bar{p} x-C\left(x, \tilde{x}^{-1}(x)\right)-\rho(x),
$$


for all $x \geq \underline{x}$, and

$$
E_{p}\left[\beta\left(p x-C\left(x, \tilde{x}^{-1}(x)\right)-\rho(x)\right)\right]=\bar{p} \underline{x}-C\left(x, \tilde{x}^{-1}(\underline{x})\right)-\rho(\underline{x}),
$$

for all $x<\underline{x}$.

\section{Summary and Discussion}

The results derived above reflect the perspective that natural resource stocks, like stocks of reproducible capital and labor, will accrue a non-zero shadow price if demand is sufficient to eliminate any excess supply in an economic sense. Physical exhaustion is not necessary for reserves to have a non-zero shadow price. As our analysis shows, this shadow price is the efficient royalty.

The analysis presented here for natural resource pricing is relevant in other contexts; the supposed inefficiency of sharecropping being an obvious example. The private sector institution of charging a fixed proportion of output for a land lease in agriculture has been criticized as inefficient since the time of Marshall and a profit-sharing scheme claimed to be more efficient. Of course, a profit-sharing scheme is more efficient if the value of the marginal product of land is zero. If agricultural use decreases the fertility of land, however, and the residual land value falls as land is more intensively used, sharecropping will be an efficient solution. Sharecropping is only one possible application of the basic reasoning. An analogous argument provides a rationalization for compensating agents (such as actors or athletes) on a percentage of gross or proportion of sales basis.

In this paper, we do not argue that "economic rents," however defined, are zero or that a profit sharing scheme (or risk sharing scheme) is inefficient. Rather, a distinction needs to be drawn between economic rent and opportunity cost, both in total and at the margin. Some of the natural resource literature has placed emphasis on the nature of the rents that accrue because natural assets are gifts from nature (Garnaut and Clunies Ross 1983, IMF 2012). This emphasis has led to the view that certain pricing schemes, such as royalties, are inefficient. Our analysis demonstrates that such a claim is not valid in general. From an economic perspective, the positive value of an asset is not affected by how it was produced, whether by nature or by industry. Resource owners (the government, in most countries) must determine when, how much, in what order, and in what use to employ their natural resource stocks. These decisions are not costless even in a frictionless world 
where reserves can be extracted at different points in time and the land or ocean that contains those reserves has alternative uses. Equally important, economic exhaustion and physical exhaustion do not coincide by necessity. Economic exhaustion may occur within the time frame of one contract, leaving reserves for future extraction or land for alternative uses.

The approach adopted here takes account of the opportunity cost of ownership and alternative use (through time and space) which implicitly has been assumed to be zero in previous analyses, leaving extraction decisions to producers who have no economic interest in the residual value of the reserves, the land or the water after extraction is completed. Thus, asset values (liquidation values) at the end of extraction may be zero for the producer both in total and at the margin.

The fact that it might be counter to the producer's interest to extract reserves during any defined contract period does not mean that those reserves will not be extracted in the future, as illustrated in Table 2. Alternatively, the opportunity cost of resource development for natural resource owners might be too high. Some landowners might prefer to use the land for other uses - for strictly monetary uses such as farming, environmental uses such as land set-asides, or the economic welfare benefits of maintaining the property.

If the marginal opportunity cost is not zero, then a price should be charged (or imputed, in the case where the extraction profile is controlled) and the resource owner should accrue that price as the return from ownership. If, however, the opportunity cost is zero, then resources are in excess risk-adjusted supply forever and the resource owner should then receive zero, at least at the margin and perhaps in total. Reserves left in the ground have no social value forever and it is not clear that even reserves extracted have any value at the margin.

Two policy implications stem from the results. First, an efficient natural resource contract may contain at least two payment types: a royalty to capture the opportunity cost and an income charge to capture rent. We do not opine on whether an income charge beyond the generally applicable income tax is desirable. ${ }^{14}$ Second, the government might have an ownership interest in natural resources and there is at best a tenuous connection between

\footnotetext{
${ }^{14} \mathrm{~A}$ profit share combined with an efficient income tax will increase the risks borne by the resource owner. Whether the expected return is sufficient to offset the cost of risk bearing needs to be addressed. This may be particularly important in countries where income is relatively low and the economy poorly diversified relative to the shareholders of large multinational firms interested in entering into extraction contracts.
} 
efficient input pricing and taxes. For example, the United States federal government does not enter into resource contracts when reserves are privately held. This simple example highlights the fact that ownership, and in turn the preferences as well as the costs of resource owners, may affect the value of the marginal payments as well as the signal created by charging a positive royalty. Governments also impose generally applicable income taxes. One purpose served by these taxes is to collect rent from all sectors. Thus, there may be no prima facie case for a special rent charge on natural resources when social opportunity cost is taken into account.

\section{References}

[1] Alexeev, Michael and Robert F. Conrad. (2014) Income Equivalence and a Proposed Resource Rent Charge, unpublished.

[2] Baunsgaard, Thomas. (2012) A Primer on Mineral Taxation. IMF Working Paper (WP/01/139) September.

[3] Boadway, R. and Keen, M. (2010) Theoretical perspectives on resource tax design, in Daniel, P., Keen, M. and McPherson, C. (eds.), The Taxation of Petroleum and Minerals: Principles, Problems and Practice. Routledge Press, United Kingdom.

[4] Conrad, R. and Hool, B. (1985) Intertemporal extraction of mineral resources under variable rate taxes, Land Economics 60(4), 319-327.

[5] Conrad, Robert F. (2014) Fiscal Policy for Natural Resources, in The Zambian Economy, P. Collier and C. Hay, eds., Oxford University Press, Forthcoming.

[6] Ernst and Young. (2012) Mongolia Mining and Tax Guide.

[7] Garnaut, R. and Clunies Ross, A. (1983) Taxation of Mineral Rents. Oxford University Press, New York.

[8] Hall, R. and Jorgenson, D. (1967) Tax policy and investment behavior, American Economic Review, 57.

[9] Hogan, L. and Goldsworthy, B. (2010) International mineral taxation: experience and issues, in Daniel, P., Keen, M. and McPherson, C. (eds.), 
The Taxation of Petroleum and Minerals: Principles, Problems and Practice. Routledge Press, New York, 122-162.

[10] Hotelling, H. (1931) The economics of exhaustible resources, Journal of Political Economy, 39, 137-175.

[11] IMF Fiscal Affairs Department (2012) Fiscal Regimes for Extractive Industries: Design and Implementation, International Monetary Fund (August 15).

[12] http://www.infomongolia.com/ct/ci/7348

[13] Leland, H. (1978) Optimal risk sharing and the leasing of natural resources, with application to oil and gas leasing on the OCS, Quarterly Journal of Economics, 92(3), 413-438.

[14] Otto, J., Andrews, C., Cawood, F., Doggett, M., Guj, P., Stermole, F., Stermole, J. and Tilton, J. (2006) Mining Royalties: A Global Study of Their Impact on Investors, Government, and Civil Society, World Bank Publications, Washington, D.C.

[15] Policy Transition Group (2010) New Resource Taxation Arrangements, Government of Australia (December).

[16] Report to the Treasurer (2009) Australia's Future Tax System, Government of Australia (December).

[17] Scott, A. (1967) The theory of the mine under conditions of certainty, in Gaffney, M. (ed.), Extractive Resources and Taxation. University of Wisconsin Press, Madison. 
Table 1. Selective Outline of Policy in Some Petroleum-Producing Countries

\begin{tabular}{|c|c|c|c|}
\hline Country & Royalty & Profits Tax & $\begin{array}{c}\text { Excess Profits } \\
\text { Charge or Charge in } \\
\text { Addition to Profits } \\
\text { Tax }\end{array}$ \\
\hline Algeria & $\begin{array}{c}\text { Variable rate } \\
5.5 \%-23 \% \text { based on } \\
\text { quantity produced } \\
\text { and zone }\end{array}$ & $\begin{array}{l}\text { Petroleum income } \\
\text { tax variable rate } 30 \% \\
-70 \% \text { based on } \\
\text { production }\end{array}$ & $\begin{array}{l}30 \% \text { if profits are not } \\
\text { reinvested. } \\
\text { (Royalties deductible) } \\
\text { Equity Participation }\end{array}$ \\
\hline Australia (Offshore) & $0 \%$ & $29 \%$ & $\begin{array}{c}40 \% \text { (Petroleum } \\
\text { Resource Rent Tax) }\end{array}$ \\
\hline Azerbaijan & $\begin{array}{c}26 \% \text { non-PSA } \\
\text { (0\% PSA) }\end{array}$ & $\begin{array}{c}\text { Negotiated rates } \\
\text { between } 25 \%-32 \%\end{array}$ & Production sharing \\
\hline Canada (Alberta) & $\begin{array}{l}\text { Sliding scale based } \\
\text { on price and quantity }\end{array}$ & $\begin{array}{c}\text { 14.36\% Provincial } \\
\text { 19.5\% Federal }\end{array}$ & None \\
\hline China & $\begin{array}{c}\text { Variable rate based } \\
\text { on production } 0 \%- \\
12.5 \%\end{array}$ & $25 \%$ & $\begin{array}{c}\text { Excess Profits Tax } \\
\text { based on production. } \\
\text { Rates vary based on } \\
\text { price. }\end{array}$ \\
\hline Ghana & $\begin{array}{c}3 \%-12.5 \% \text { based on } \\
\text { agreement }\end{array}$ & $\begin{array}{c}50 \% \text { on upstream } \\
\text { activities }\end{array}$ & $\begin{array}{l}\text { Minimum carried } \\
\text { interest of } 10 \% \\
\text { A type of Resource } \\
\text { Rent Tax, rates } \\
\text { depend on contract. }\end{array}$ \\
\hline Indonesia & $0 \%$ & $25 \%$ & $\begin{array}{l}\text { Production Sharing. } \\
\text { Rates vary by } \\
\text { contract. There are } \\
\text { cost limitations. }\end{array}$ \\
\hline Iraq & $\begin{array}{l}0 \% \text { (Service } \\
\text { Contract) }\end{array}$ & $35 \%$ & $\begin{array}{c}\text { Service Contract with } \\
\text { remuneration based } \\
\text { on internal rates of } \\
\text { return }\end{array}$ \\
\hline Kazakhstan & $\begin{array}{l}2 \%-6 \% \text { based on } \\
\text { production }\end{array}$ & $30 \%$ & $\begin{array}{l}\text { Rate varies from } 0 \text { to } \\
60 \% \text { based on ratio of } \\
\text { accrued revenue to } \\
\text { accrued expenses } \\
\text { (Not applicable for } \\
\text { production sharing) } \\
\text { Production Sharing } \\
\text { rates based on } \\
\text { internal rates of } \\
\text { return and pay backs }\end{array}$ \\
\hline The Netherlands & $\begin{array}{c}\text { Variable Rate (0\%- } \\
7 \%) \text { based on } \\
\text { production }\end{array}$ & $25 \%$ & $\begin{array}{l}50 \% \text { ring-fenced } \\
\text { measure of profits }\end{array}$ \\
\hline Nigeria & $\begin{array}{c}0 \% \text { - } 12 \% \text { based on } \\
\text { depth of offshore } \\
\text { deposit }\end{array}$ & $30 \%$ & $\begin{array}{l}85 \% \text { on exports and } \\
65.5 \% \text { on domestic } \\
\text { sales based on } \\
\text { measured profits less }\end{array}$ \\
\hline
\end{tabular}




\begin{tabular}{|c|c|c|c|}
\hline Country & Royalty & Profits Tax & $\begin{array}{c}\text { Excess Profits } \\
\text { Charge or Charge in } \\
\text { Addition to Profits } \\
\text { Tax }\end{array}$ \\
\hline & & & incentives \\
\hline Norway & 0 (abolished 2006) & $28 \%$ & $\begin{array}{c}50 \% \text { "Special Tax on } \\
\text { extraction, processing } \\
\text { and pipeline } \\
\text { transport" }\end{array}$ \\
\hline $\begin{array}{l}\text { United States } \\
\text { (Offshore) }\end{array}$ & $\begin{array}{c}\text { 1/6 (Revenue less } \\
\text { short term lifting } \\
\text { cost) }\end{array}$ & $35 \%$ maximum rate & None \\
\hline United Kingdom & 0 (abolished 2003) & $23 \%$ maximum Rate & $\begin{array}{l}32 \% \text { ring-fenced cash } \\
\text { flow }\end{array}$ \\
\hline Venezuela & $30 \%$ & $50 \%$ & $\begin{array}{l}\text { Equity Participation } \\
\text { and Production } \\
\text { Sharing. Production } \\
\text { sharing has variable } \\
\text { rate based on internal } \\
\text { rate of return. }\end{array}$ \\
\hline
\end{tabular}


Table 2: Examples of Mines that Have Been Closed but Reopened at a Later Date

\begin{tabular}{|l|c|c|c|}
\hline \multicolumn{1}{|c|}{ Name and Location of Mine } & Opened & Closed & Reopened \\
\hline $\begin{array}{l}\text { Affinity Mine } \\
\text { West Virginia, US }\end{array}$ & 1951 & 1985 & 2011 \\
\hline $\begin{array}{l}\text { Continental Pit } \\
\text { Montana, US }\end{array}$ & 1980 & 2000 & 2003 \\
\hline $\begin{array}{l}\text { Copperstone Mine } \\
\text { Arizona, US }\end{array}$ & 1987 & 1993 & 2011 \\
\hline $\begin{array}{l}\text { Hemerdon (or Drakelands) Mine } \\
\text { Devon, England }\end{array}$ & 1917 & 1944 & 2014 \\
\hline $\begin{array}{l}\text { Hycroft Mine } \\
\text { Nevada, US }\end{array}$ & 1880 s & 1998 & 2008 \\
\hline $\begin{array}{l}\text { Kingman Mine } \\
\text { Arizona, US }\end{array}$ & 1970 & 1983 & 2004 \\
\hline $\begin{array}{l}\text { Népoui-Kopéto Mining Centre } \\
\text { New Caledonia }\end{array}$ & 1883 & 1991 & 2012 \\
\hline $\begin{array}{l}\text { Pueblo Viejo Mine } \\
\text { Dominican Republic }\end{array}$ & 1865 & 1997 & 2014 \\
\hline $\begin{array}{l}\text { Shafter Silver Project } \\
\text { Texas, US }\end{array}$ & & 1942 & \\
\hline $\begin{array}{l}\text { White Pine } \\
\text { Michigan, US }\end{array}$ & & 1994 \\
\hline
\end{tabular}

\footnotetext{
${ }^{1}$ Coal. http://www.register-herald.com/news/local news/affinity-mine-reopens-with-fanfare/article c1d19d12-758f5594-8628-41823e38a94b.html (accessed 31 August 2015)

${ }^{2}$ Copper. http://www.deseretnews.com/article/595076167/Mine-reopening-lifts-battered-Butte.html?pg=all (accessed 31 August 2015)

${ }^{3}$ Gold. http://www.kerrmines.com/projects/copperstone-mine (accessed 31 August 2015)

${ }^{4}$ Tungsten. https://en.wikipedia.org/wiki/Hemerdon_Mine (accessed 31 August 2015)

${ }^{5}$ Gold and silver. http://www.alliednevada.com/properties/hycroft-mine/ (accessed 31 August 2015)

${ }^{6}$ Turquoise. http://www.silversunalbuquerque.com/turquoise-mines/Kingman (accessed 31 August 2015)

${ }^{7}$ Nickel. http://www.eramet.com/sites/default/files/eramet_nickel_division_mining_centres.pdf and http://www.sln.nc/nepoui-kopeto (accessed 31 August 2015)

${ }^{8}$ Gold. http://www.mining-technology.com/projects/pueblo-viejo-gold-mine/ (accessed 31 August 2015)

${ }^{9}$ Silver. http://www.aurcana.com/operations/overview/ (accessed 31 August 2015)

${ }^{10}$ Copper. http://www.highlandcopper.com/s/white_pine north.asp (accessed 31 August 2015)
} 